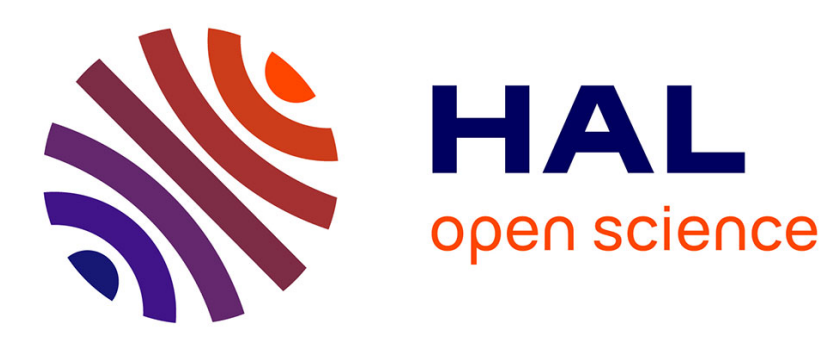

\title{
Emergy-based mid-point valuation of ecosystem goods and services for life cycle impact assessment
}

B. Rugani, E. Benetto, Damien Arbault, L. Tiruta-Barna

\section{To cite this version:}

B. Rugani, E. Benetto, Damien Arbault, L. Tiruta-Barna. Emergy-based mid-point valuation of ecosystem goods and services for life cycle impact assessment. Revue de Métallurgie, 2013, 110 (4), pp.249 - 264. 10.1051/metal $/ 2013067$. hal-01268442

\section{HAL Id: hal-01268442 \\ https://hal.science/hal-01268442}

Submitted on 29 May 2020

HAL is a multi-disciplinary open access archive for the deposit and dissemination of scientific research documents, whether they are published or not. The documents may come from teaching and research institutions in France or abroad, or from public or private research centers.
L'archive ouverte pluridisciplinaire HAL, est destinée au dépôt et à la diffusion de documents scientifiques de niveau recherche, publiés ou non, émanant des établissements d'enseignement et de recherche français ou étrangers, des laboratoires publics ou privés.

$$
\text { Copyright }
$$




\title{
Emergy-based mid-point valuation of ecosystem goods and services for life cycle impact assessment
}

\author{
B. Rugani ${ }^{1}$, E. Benetto ${ }^{1}$, D. Arbault ${ }^{1,2,3,4}$ and L. Tiruta-Barna ${ }^{2,3,4}$ \\ 1 Public Research Centre Henri Tudor (CRPHT)/Resource Centre for Environmental Technologies \\ (CRTE), 6A avenue des Hauts-Fourneaux, 4362 Esch-sur-Alzette, Luxembourg \\ e-mail: benedetto.rugani@tudor.lu \\ 2 Université de Toulouse, INSA, UPS, INP, LISBP, 135 avenue de Rangueil, 31077 Toulouse, France \\ 3 INRA, UMR 792, Laboratoire d'Ingénierie des Systèmes Biologiques et des Procédés, 31400 Toulouse, \\ France \\ 4 CNRS, UMR 5504, 31400 Toulouse, France
}

\section{Key words:}

Ecosystem goods and services; emergy; characterization factor (CF); life cycle assessment (LCA); life cycle impact assessment (LCIA); resource; unit emergy value (UEV)
Received 29 March 2013 Accepted 29 May 2013

\begin{abstract}
Ecosystem goods and services (EGSs) are of crucial importance for the economic and social development of human communities. The well-established life cycle assessment (LCA) method is facing a number of challenging improvements to define new Characterization factors (CFs) for life cycle impact assessment (LCIA) of EGSs. Very recently, extensive work conducted under the UNEP/SETAC Life Cycle initiative has been completed with the goal of providing new LCIA methods and spatially differentiated mid-point CFs for land use and land use change impacts on biodiversity and ecosystem services. However, the implemented models do not enable one to assess the actual damage to ecosystem functionality, and thus the relationship among EGSs and related areas of protection (e.g. AoP of "Natural Resources") remains undefined. This paper aims at investigating the potential characterization ability of the Emergy method for LCIA of EGSs. The goal is to use the extensive libraries of Unit Emergy Values (UEVs) of primary services and resources as CFs for LCIA to evaluate the physical contribution of EGSs in supporting life cycle processes. Having its roots in thermodynamics and systems ecology, Emergy can appraise a larger and more diversified (than LCA) number of EGSs through a common physical denominator, i.e. the solar emjoule or seJ, which measures the solar energy embodied in natural products. Emergy thus has a typical Nature-oriented perspective, accounting for the available energy that is used up by the natural cycles, directly and indirectly, to generate biotic and abiotic resources. A library of selected UEVs (more than 100) for biophysical EGS valuation has been framed including values collected from the Emergy literature and formulated on the latest planetary baseline (i.e. 15.2E + $24 \mathrm{seJ} / \mathrm{yr}$ ). Advantages and limitations for future application of these values toward an LCIA mid-point impact characterization of Emergy are discussed. UEVs may represent mid-point LCIA factors for ecological contribution analysis, enabling one to account for the memory of energy previously required to produce EGSs, which can be used as a proxy to assess the future environmental work necessary to regenerate the used EGSs. However, the added value of Emergy for LCA is still debated, mainly because of the low accuracy and unclear meaning of the UEVs in relation to the availability of resources. Therefore, Emergy can be conceived as a suitable physical measure complementary to the economic valuations and current "user-side" tools applied in LCA.
\end{abstract}

\section{Introduction}

The Millennium Ecosystem Assessment, which is the worldwide reference and most comprehensive survey presenting the state of Earth's ecosystems, defines and classifies the ecosystem goods and services (EGSs) into four domains as follows [1]: provisioning services (i.e. products directly obtained from ecosystems, e.g. freshwater, fossil fuels and minerals, timber, food, genetic resources and wild plants, natural medicines), supporting services (i.e. services required to deliver and support all the other ecosystem services, e.g. soil formation, primary production, photosynthesis, nutrient cycling), regulating services (i.e. benefits obtained from the regulation of ecosystem processes, e.g. air quality regulation, water purification and regulation, climate regulation, erosion regulation, pest and disease regulation, pollination, carbon sequestration), and cultural 


\section{List of acronyms}

\begin{tabular}{|ll|}
\hline AoP & Areas of Protection \\
CFs & Characterization Factors \\
EGSs & Ecosystem Goods and Services \\
Em\$ & Emdollars \\
EmR & Emergy-to-money Ratio \\
ESV & Ecosystem Services Valuation \\
GDP & Gross Domestic Product \\
HH & Human Health \\
LCA & Life Cycle Assessment \\
LCI & Life Cycle Inventory \\
LCIA & Life Cycle Impact Assessment \\
LU & Land Use \\
NE & Natural Environment \\
NR & Natural Resources \\
PDF & Potentially Disappeared Fraction \\
UEV & Unit Emergy Value \\
\hline
\end{tabular}

services (i.e. cultural, spiritual, religious, recreational and other non-material benefits people may obtain from ecosystems).

Whereas EGSs are of crucial importance for the production of commodities and for the economic and social development of human communities $[2,3]$, their value accounting is usually neglected by the conventional economic and social-based indicators (e.g. Gross Domestic Product-GDP) and also by the most used environmental impact assessment methodologies, such as Life Cycle Assessment (LCA).

LCA is a widely accepted and standardized methodology to evaluate the life cycle environmental impacts of systems and products $[4,5]$. The Life Cycle Impact Assessment (LCIA) is the downstream phase of a LCA where the life cycle inventoried environmental interventions (i.e. elementary flows of resource extractions and pollutant emissions modeled within the Life Cycle InventoryLCI phase) are converted to potential impacts and damage through the use of specific Characterization Factors ( $\mathrm{CFs}$ ).

The LCA method is facing a number of challenging improvements to define new CFs for LCIA at the mid-point (potential impact) and/or end-point (damage) levels of the cause-effect chain. The LCIA reflects the values defined as three areas of protection (AoP): "Human Health" (HH), "Natural Resources" (NR) and "Natural Environment" (NE) $[4,6]$. Whereas there is a general acceptance on the scope of the first AoP, the evaluation of NR and NE remains a highly debatable issue. A clear distinction between these two AoP does not exist, because they are intrinsically linked [6,7]. The extraction of resources, such as mineral deposits, fossil energy carriers, fish, trees and water has many repercussions on the environment. The extracting activity in itself (e.g. mining, forestry, fishery) can also release toxic emissions, create noise, damage the landscape, etc., which are dealt with under other AoP [6]. Moreover, the definition of the NR AoP has not yet been properly formulated, because it may rely upon several issues. First, it is not clear whether the damage should be evaluated only for the removal of resources that are necessary for human purposes (i.e. anthropocentric and utilitarian perspective) or should also include aspects of protection for the other species and ecosystems (i.e. Nature-oriented perspective). For instance, while humans could live without trees in some regions, squirrels and other mammals and insects cannot survive without the existence of trees [6]. Second, there are high degrees of uncertainty in forecasting future availability of resources and functioning of ecosystem services, which have inherent effects on their scarcity and damage. This is basically due to partial agreement and/or scarce knowledge about future technologies of extraction and resource consumption behaviors, which mostly depend on the human population growth and needs in developing countries. The AoP of NR is therefore addressed to assess the damage to the productivity of the ecosystems, i.e. the damage to resources or ecosystem goods.

Accordingly, several LCIA indicators have been developed to evaluate the role of resources for human purposes e.g. [8-15]. The most recommended approach is based on the notion of scarcity, which is assessed by evaluating the future marginal cost of extraction/use of the resources [14,15]. Basically, it is assumed that extracting a high concentration of resources today will force future generations to extract a lower concentration or lower value resources [6]. This results in the need for additional efforts, i.e. higher energy or costs, which leads to an 
increased impact on the environment and economy $[6,14,15]$. With regard to the AoP of NE, the aim is to quantify the negative effects on the function and structure of natural ecosystems as a consequence of exposure to chemicals or physical interventions [6]. This end-point impact is usually addressed by applying the potentially disappeared fraction (PDF) of species, which is the recommended indicator to quantify the loss of biodiversity due to chemical exposure [6]. However, the PDF indirectly depends on the Land Use (LU), which is a mid-point impact category that may also be used to account for the availability of resources, thus influencing the AoP of NR. Indeed, the LU reflects the damage to ecosystems due to the effects of occupation and transformation of land [6] and is currently considered as the starting point to improve the approach of EGSs evaluation in LCA.

Very recently, comprehensive work conducted under the UNEP/SETAC Life Cycle initiative [16] has been completed with the goal of providing a set of LCIA methods and spatially differentiated CFs for LU (i.e. land occupation) and LU change (i.e. land transformation) impacts on biodiversity and ecosystem services in a comprehensive way to assess e.g. biodiversity damage [17], climate regulation [18], biotic production [19], erosion and freshwater regulation, and water purification potential [20]. Despite this great effort, however, the implemented methods still only assess a "potential" impact at the mid-point level, whereas the actual damage to ecosystem functionality and productivity and the relation between different EGSs and the AoP of NR and NE remain undefined and a challenge to achieve. One of the main goals reached by the UNEP/SETAC Life Cycle initiative is the definition, harmonization and ranking of a large set of LU and LU change elementary flows created as a common inventory database for both global and local assessments. This is undoubtedly a great achievement toward a standardized classification and regionalization of LU inventories and impact assessment methods, because it provides for the first time the necessary flexibility to providers of inventories and to developers of impact assessment methods and overcomes the problems of mismatching definitions between the two [21]. However, the LCA method also shows weak points related to the completeness of inventory for EGSs. Conventionally, the evaluation of EGSs in LCA has been focused only on a few provisioning services or ecosystem goods [7-22], neglecting to account for regulating, supporting and cultural services. For example, the largest LCI database worldwide, i.e. Ecoinvent [23], accounts for hundreds of ecosystem goods (e.g. mostly fossil fuels and minerals, and few elementary flows of freshwater, wood and renewable energy), but does not model any link to other ecosystem services such as water and climate regulation, nutrient cycles, pests and diseases, pollination, soil formation, photosynthesis, etc. These EGSs are crucial for the production e.g. of agri-food and forestry products, but they are ultimately not inventoried by using physical metrics in LCI.

Beyond LCA, other environmental accounting tools have been developed to assess the value of ecosystems. For example, the Emergy analysis method developed by H.T. Odum [24,25] is considered one of the most comprehensive common denominators for biophysical evaluations of EGSs [26-31]. Indeed, emergy measures the human and environmental work previously required to generate products and services [25]. In other words, Emergy encompasses the entire system boundaries of the Earth, because it accounts for the ultimate independent sources of energy that feed all the natural cycles: sun, tides and crustal heat. Emergy is thus able to approximate the environmental work necessary to replace what is used, presenting a unified measure of resource consumption, i.e. the solar energy directly and indirectly driving all geobiosphere processes [32]. The unit emergy value (UEV) represents the conversion factor to calculate the Emergy content of any kind of good or service. For LCA purposes, interest is addressed toward the use of UEVs as CFs for LCIA based on Emergy [10,32,33]. In such a way, the use of Emergy principles could benefit and expand the calculation of EGSs in LCA [34,35].

The aim of this work is to outline possible research paths in the analysis of the 
contribution of EGSs to life cycle products by using the Emergy method. Accordingly, the rest of the paper is organized as follows: the Emergy accounting procedure is briefly illustrated and a state-of-the-art is then given with regard to the main attempts performed to valuate EGSs with an Emergy-oriented approach. Afterwards, a library of UEVs for EGSs mid-point assessment is provided, where values are collected from the literature and their meaning investigated in accordance with the requirements of the most used LCI databases. Finally, conclusions are drawn according to the main limitations, advantages and possible follow-ups of the methodology.

\section{Emergy concept and evaluation procedure}

In its conventional definition, Emergy, spelled with an " $\mathrm{m}$ ", represents the of available energy used up in the entire chain production and incorporates the solar energy previously required to generate a product and/or to support a system and its level of organization [25]. Emergy is indeed the memory of the (solar) energy that has been used in the past or accumulated over time, or the memory of the geobiosphere Exergy provision (environmental work) related to economic systems via the use of natural resources $[36,37]$. Emergy stems from the qualitative and quantitative consideration that all different forms of energy can be hierarchized and measured with the common metric of the solar emjoule (seJ) $[24,25]$. To convert material and energy items into seJ, the method uses a conversion factor called transformity or unit emergy value (UEV), which is the Emergy required to make one unit of a given product or service $[24,25]$ (see later in Sect. 3).

The calculation of UEVs is rooted in the "Baseline" concept [38,39]. This concept states that resource stocks and flows are coproducts of the same global Emergy budget (i.e. baseline) that drives all geobiosphere processes (see Fig. 1). The Emergy baseline is the sum of solar radiation Emergy, tide Emergy, and geothermal heat Emergy. In order to assign an Emergy value (i.e. equivalents of joules of solar energy) to these three different sources, a number of (linear) balance equations are initially applied $[38,39]$. As a result, the Emergy of 1 unit of tidal energy absorbed and of 1 unit of crustal heat is 72400 and 20300 times higher, respectively, than the emergy of 1 unit of solar energy absorbed [39]. This means that 72400 and 20300 joules of solar energy are assumed to make, respectively, 1 joule of tidal energy absorbed and 1 joule of energy from crustal heat sources. The total annual baseline is therefore composed of $24 \%$ of solar Emergy, $54 \%$ of tidal Emergy, and 22\% of geothermal Emergy. As described in Section 3, the baseline is used to quantify the different EGSs with a hierarchical perspective (i.e. the larger the amount of the ecosystem good or service, the lower the UEV). Since the UEVs are applied afterwards to convert the energy and material inputs to human products and systems into seJ, other UEVs are then quantified in cascade (i.e. input Emergy divided by the output) and can be used for further applications.

\section{Emergy and ecosystem services}

Ecosystems are supported by continuous flows of Emergy, which ensure their functioning and dynamics and the provision of goods and services to sustain humans and other species. Emergy is thus considered to have "donor" features, because it expresses the role of a free ecological contributor to global and local equilibria in the geobiosphere. The anthropic technosphere is a primary receiver of, and strictly depends on those "not priced" Emergy inputs from the ecosystems. However, the role of humans in the geobiosphere is strongly utilitarian and not counterpart to that of other species. As a result, ecosystem goods and services are acknowledged only for the benefit they can give to technology development, which means the value of natural resources is weighted on their unique quality of being competitive for human purposes (e.g. quantity of Energy or Exergy that can be used or extracted). Therefore, the willingness to pay for the ecological contributions is based only on the intrinsic ability of the ecosystem services to provide benefits for humans, while the remaining but essential rucksack 


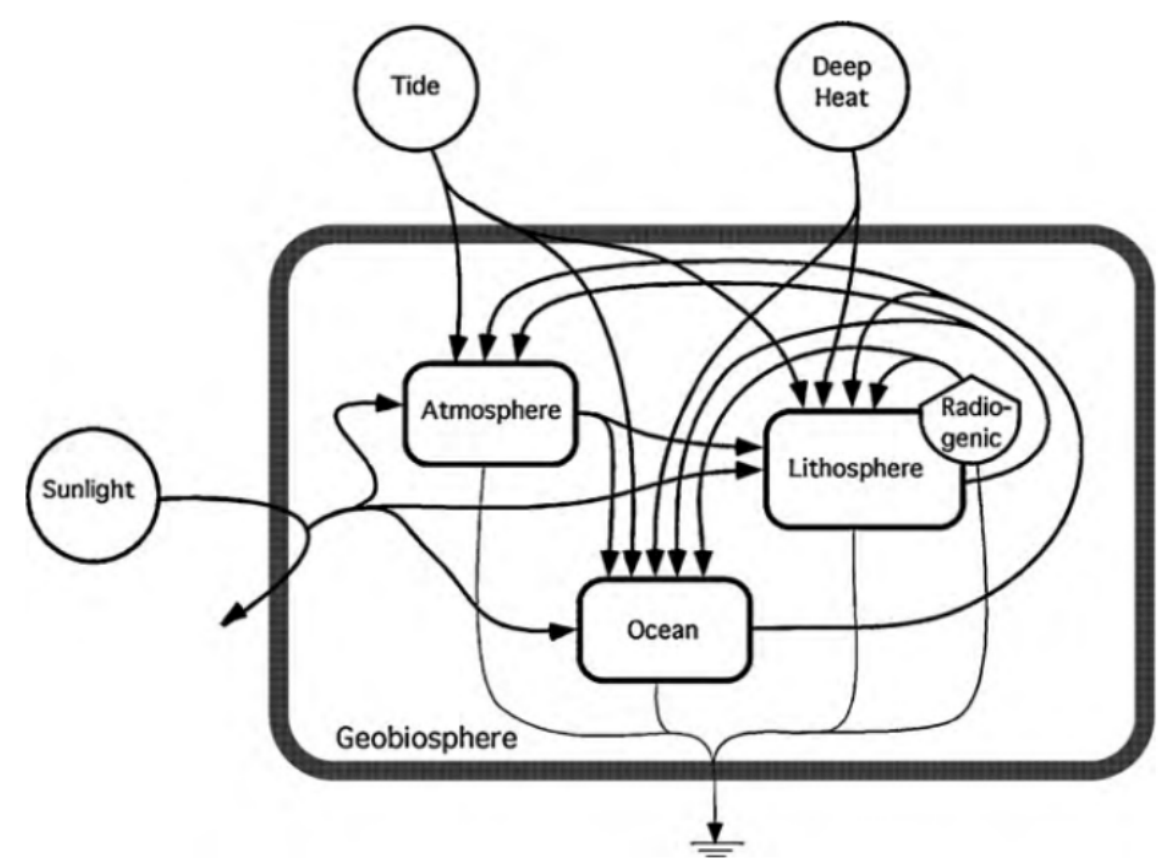

Fig. 1. Hierarchical web of components in the Earth's geobiosphere, connected by flows of available energy independently supplied by sunlight, deep heat and tide sources (source: [39]).

of complexity, information, ability to support other species and to regulate natural equilibria, in other words "the natural effort", is usually neglected. Emergy attempts to overcome this lack.

Many studies have suggested Emergy as a promising tool to support environmental management actions and public planning policies, because of its ability to characterize the dynamics of territorial systems e.g. $[40,41]$. According to Odum and Odum [30], Emergy-based valuation would avoid neoclassical approaches that "would not capture real contributions of ecosystems and could delay the organization of a sustainable pattern of environment and people". Conventional approaches related to ecological economics, such as willingnessto-pay based on the contingent valuation method, usually capture the value of ecosystem entities narrowly and anthropocentrically, while in contrast, Emergy tries to estimate their ecocentric value $[29,42]$. Several authors have attempted to estimate this value from a physical perspective. During the past decade, Ulgiati, Brown and coauthors tried to determine the natural capital required for the development of human systems [28, 43, 44], and also to estimate the ecosystem services necessary to support waste dilution and abatement [45]. Watanabe and Ortega have recently quantified several UEVs for ecosystem services related to water, carbon and nitrogen cycles on the global scale [29]. Other scholars actively contributed to give insights on how to assess the EGSs' influence on a high diversity of natural and human-driven systems from a biophysical Emergy perspective, such as wastewater treatment performances [46], estuarine ecosystem networks [47], river diversions [48], and peri-urban systems [49]. For this latter, in particular, the authors provided a comprehensive land cover change analysis to assess the decrease in EGSs provision on a very local scale, providing methodological findings in terms of effective spatial plans for controlling urban growth while protecting ecosystem functions. A study of linked relevance to this context is that performed by Montesino, who tried to explicitly account for the Emergy of several EGSs (i.e. biomass production, pollination, pest control, erosion control, nitrogen cycle, water cycle, carbon sequestration, biodiversity, aesthetic services) required in Danish agricultural systems of energy crops [50], providing a sort of "mid-point" assessment. 
Emergy analysis is also able to integrate, in seJ, all flows within a system of coupled economic and environmental work, facilitating direct comparisons between natural and human-made capital [25, 51, 52]. Because goods and services are exchanged in the technosphere by means of money, Emergy adopts an artificial method to convert the seJ into the regional currency in order to estimate the apparent cost of ecological contributions to human processes. Accordingly, the Emergy-to-money Ratio (EmR, in seJ/\$ or other currency) has been implemented, which is the ratio of Emergy use in a country or a region to its GDP. The EmR estimates the amount of Emergy that, on average, is necessary to obtain one unit of money produced in a region, and therefore it represents the environmental cost associated with the economic wealth of that region. The output Emergy can be divided by the average EmR of an economic system to translate the seJ into Emdollars (Em\$). Therefore, the Em\$ becomes a metric familiar to the market language and makes Emergy comparable with cost-benefit and economic analyses [25-27, 52].

Several Emergy studies have been performed to evaluate the cost of EGSs in terms of Em\$. For example, Tilley and Swank [53] investigated in depth the benefits provided by the wine spring creek (WSC) forested watershed (southern Appalachian Mountains of North Carolina, USA) for the local economy, environment and society, while Cohen et al. performed an in-depth investigation of the Emergy environmental and economic costs of soil erosion losses on different scales in Kenya [51]. Odum et al. [54] quantified the net public benefit of reforestation alternatives in Puerto Rico, finding that natural wealth accumulated to a level 15-25 times the money invested in the 10-20 yrs required for canopy closure. Other authors, instead, studied dam construction projects, which often induce significant ecological and environmental change, to assess how the functional benefits of water supply, flood control and power production compare with ecosystem and agricultural losses $[55,56]$.

More recently, Pulselli et al. [27] compared the Emergy outcomes of EGSs analysis with those resulting from the application of conventional techniques of ecosystem services valuation (ESV) as provided in reference [3]. They found that, globally, Nature contributes to humans not only more (as in Ref. [3]), but in a more efficient way, than all the world's economic infrastructures [27]. So far, Emergy would not be an alternative method to ESV techniques, but rather a complementary and systemic approach to highlight the mechanisms of service production by different systems [27]. Indeed, current economic ESV methods consist of "internalizing externalities" by devising approaches to value non-market-traded goods and services [57]. Odum and Odum [30] suggest that we need to "externalize the internalities" by using solar energy as the basis for valuing goods and services provided by our natural and human environments; therefore, Emergy could potentially fill a significant gap in adequately valuing EGSs and managing natural environments better. The Em\$ might be a useful metric to assess the endpoint framework in the use of EGSs. However, its meaning and effectiveness for environmental policies must be better clarified and more widely accepted.

\section{Emergy-based mid-point LCIA factors}

As mentioned before, Emergy is able to distinguish and compare the work done by humans with the work done by Nature. Both of them can be accounted for in joules of equivalent solar energy, and portions of renewability and non-renewability depicted. As a result, a large number of UEVs for natural and technological products are made available. In the former case, the effort of Nature in generating the ecosystem good or service is quantified per unit of product (i.e. biosphere resource UEVs), while in the latter case, the amount of natural investment is added to the amount of human investment to produce the final market good or service product (i.e. technosphere product UEVs).

To obtain technosphere product UEVs with a LCA perspective, the biosphere resource UEVs can be retrieved and used as $\mathrm{CFs}$, thus allowing an Emergy-based LCIA [10]. The resource UEVs are usually representative of large-scale natural 
processes or global cycles. An established procedure to set for the flows (i.e. inputs of elements, raw materials, natural energy carriers, and outputs) to be included in the UEV inventory does not exist, due to the large complexity of the natural systems: modeling for ecosystem dynamics is inherently very complex and subject to high degrees of uncertainty.

The approach of accounting for a UEV or a group of UEVs of EGSs is based on variable paths and assumptions. The current accepted and common feature remains the use of the "baseline". Since solar energy is the primary source that feeds all processes and cycles on the Earth, inputs to a process can be normalized to a common unit, i.e. the seJ, which is the common (physical) numeraire to account for the value of EGSs in Emergy. Therefore, to assess the ecosystem contribution to a life cycle production system, all inputs of EGSs can be converted into Emergy flows via

$$
\mathrm{UEV}_{i}=C F_{i}=\frac{S}{F_{i}}
$$

and

$$
F_{i}=\frac{Q_{i}}{\Delta T_{i}}
$$

where $\mathrm{UEV}_{i}$ is the Unit Emergy Value of the $i$ th ecosystem good or service flow (in seJ/g, $\mathrm{seJ} / \mathrm{m}^{3}$, seJ/J, etc.), which can be adopted as the characterization factor $\left(C F_{i}\right)$ for midpoint Emergy-based LCIAs; $S$ is the Emergy baseline $(=15.2 \mathrm{E}+24 \mathrm{seJ} / \mathrm{yr}$; see $[38,39]$ for the comprehensive mathematical derivation of this number); $F_{i}$ is the annual provision (or amount) of the $i$ th ecosystem good or service flow on the global scale (in $\mathrm{g} / \mathrm{yr}, \mathrm{m}^{3} / \mathrm{yr}, \mathrm{J} / \mathrm{yr}$, etc.); $Q_{i}$ is the estimated storage (or global capacity) of the $i$ th ecosystem good or service (in $\mathrm{g}, \mathrm{m}^{3}$, J, etc., in particular with regard to provisioning services or resources); and $\Delta T$ is the turnover time or estimated regeneration rate, in yrs (accordingly, a renewable resource is assumed when $\Delta T=1 \mathrm{yr}$ ). In this connection, the notion of time is usually referred relatively to the state of the geological or biological (estimated) time of formation, which corresponds to the turnover time of the resource as being potentially regenerated from scratch (e.g. 5.19E +08 yrs in the case of granitic rock, [25]). The variables expressed in equations (1) and (2), in particular with regard to the amount of stock of the resources (e.g. groundwater, crude oil or iron reserves on the global scale), can be retrieved from the extant literature on global geobiosphere processes and Earth cycles (see in $[25,28,39]$ for a more in-depth overview of the available sources). Therefore, their accuracy and representativeness depends on the quality of estimations included in those sources of biogeophysical and natural resource datasets.

In the Emergy literature, a large number of UEVs of natural resources is available [10], such as for water flows and storage [58], renewable energy resources such as wind or geothermal heat, biomass resources, different kinds of minerals and fossil fuels $[25,38,59]$. A summary of resource flow UEVs has been provided by Brown and Cohen [60]. Recently, UEVs were calculated for a large number of metal ore resources [61]; besides this, the calculation for fossil resources of gas, crude oil and coal was also upgraded [62]. These are all ecosystem goods that can be regarded as provisioning services and further used for LCIA purposes. Accordingly, the most used LCI databases such as Ecoinvent [23], or the recent International European reference life cycle database (ELCD) [63], usually include a large number of resource extraction elementary flows, both of biotic and abiotic nature. In Table 1, a simplified illustration of these two LCI databases with regard to provisioning services (i.e. elementary flows of resource) is reported, with a comparison in terms of number of ecosystem goods accounted for and levels of classification (i.e. category detail). Both the datasets include a large number of flows (i.e. \#287 and \#165 in the Ecoinvent v2.2 and ELCD, respectively), but the focus is mainly on nonrenewable resources such as minerals, metals and fossil fuels. The evaluation of biotic flows as well as water and renewable energy is quite scarce in both cases. Moreover, while Ecoinvent accounts for many flows of LU (more than 130), the ELCD explicitly distinguishes between non-renewable and renewable resources.

In Table 2, an extensive library of UEVs of EGSs is provided, which might be used as mid-point characterization factors for 
B. Rugani et al.: Revue de Métallurgie 110, 249-264 (2013)

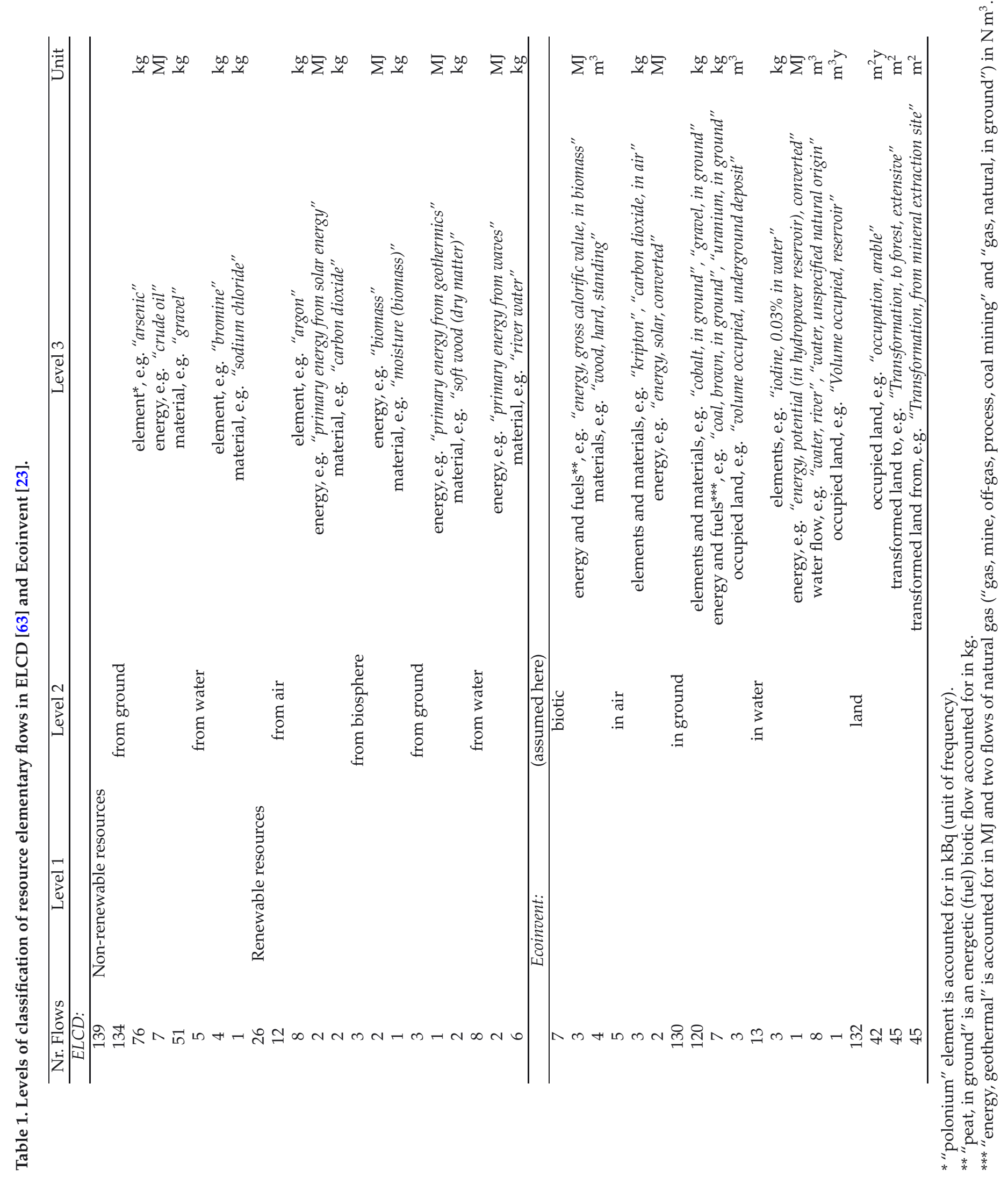




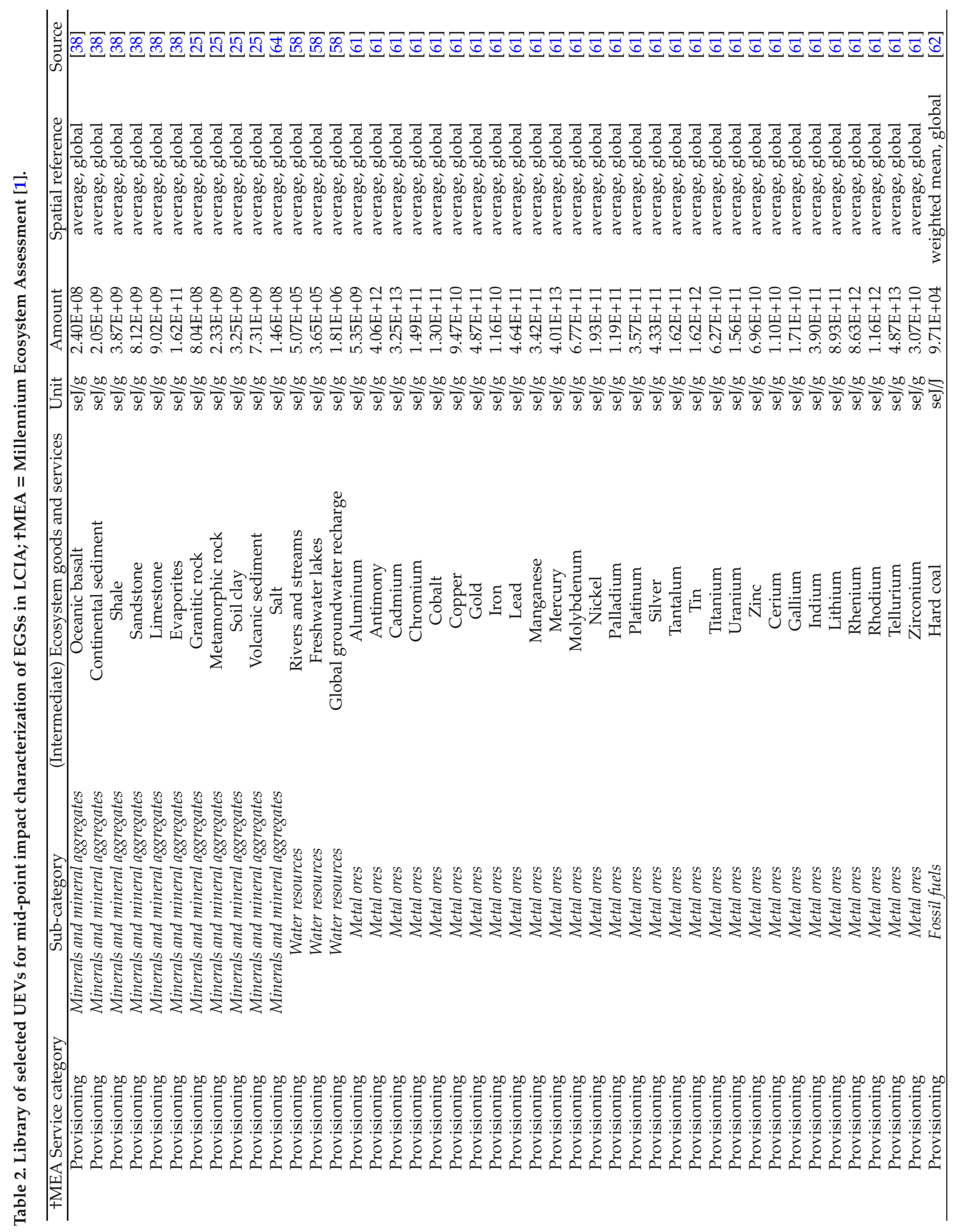




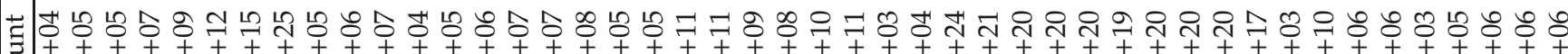

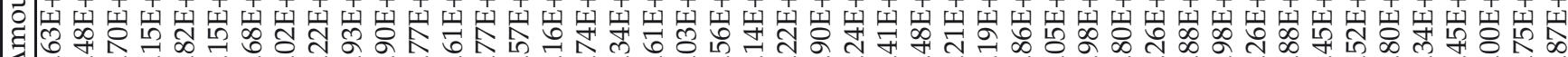

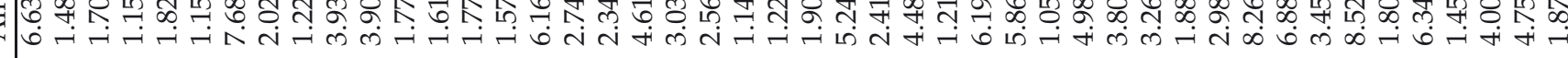

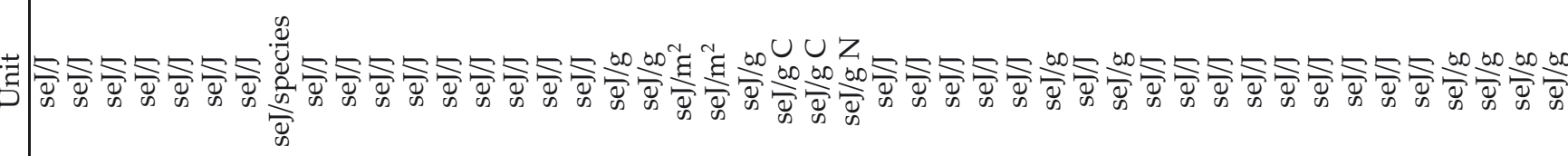

疍

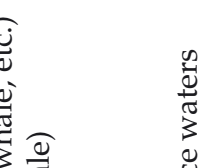

离

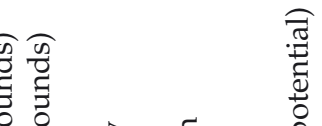
焉

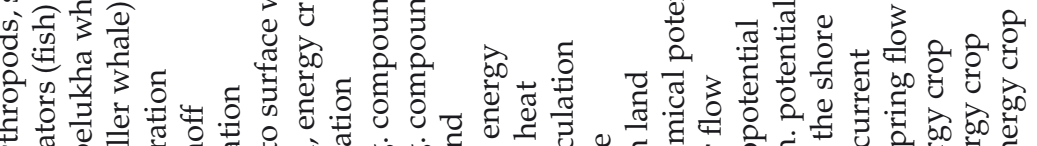

\& 4 \& 


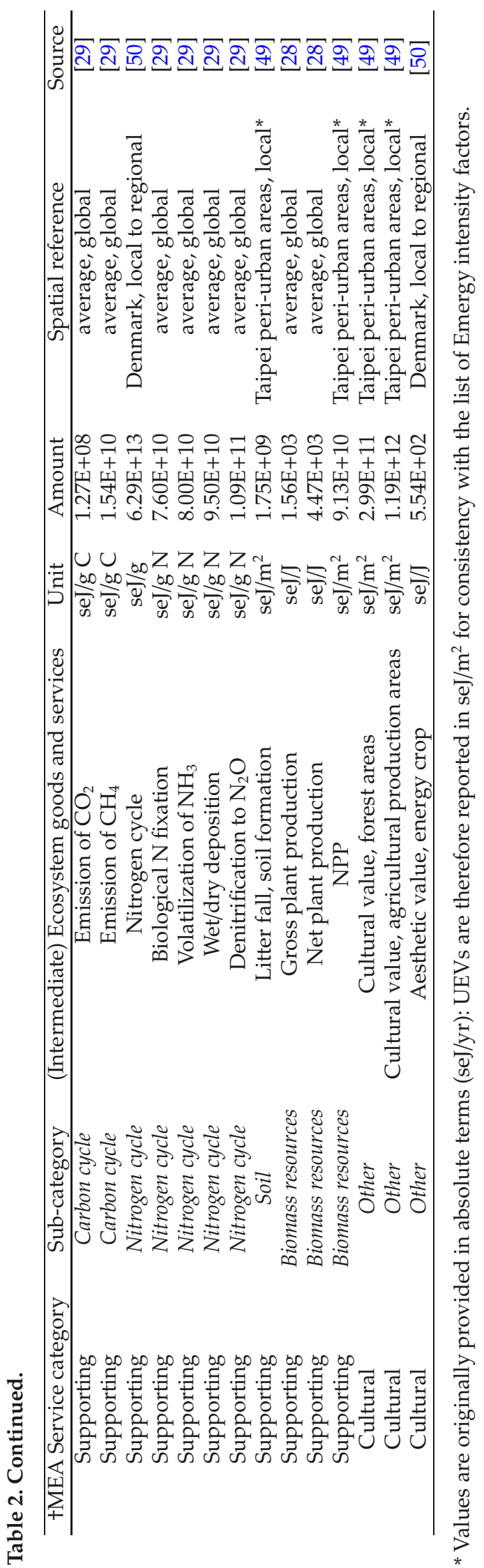

Emergy evaluation in LCIA. The UEVs are grouped into the four categories of provisioning, supporting, regulating and cultural services. Each UEV has been collected from the most recent Emergy literature and re-set (when not already given as such) on the latest quantified planetary baseline $(=15.2 \mathrm{E}+24 \mathrm{seJ} / \mathrm{yr}$, [39]). This library represents a preliminary version, including a limited selection of UEVs (more than 100 elementary flows). Most of them can be regarded as provisioning services. Of course, other studies might be consulted in the future to update this list and to provide more specific UEVs. The time frame is not considered (there is not a reference year of calculation), while a rough reference condition for the spatial scale is provided (from global to local, when available).

\section{Outlook on limitations and advantages}

By definition, Emergy aims to extensively account for natural processes, both at the global (e.g. atmospheric processes, land uplift, ocean current circulation) and regional scales (e.g. water runoff, soil erosion, surface wind, precipitations) $[38,52]$. Despite this stated aim, the use of the baseline concept does not provide enough accuracy and detail on which processes are actually considered and how. Literature studies, rather than overtly rebut the baseline concept, provide a number of baseline values where components (i.e. sun, tide, geo) are weighted differently $[25,38,39,66]$. Sciubba identified several uncertainty issues behind the Emergy calculation of the three primary inputs to the geobiosphere, highlighting the potential ability of Exergy to compute the real "cost" of each component to the biosphere [67]. Since UEVs are calculated through a sort of pyramidal process starting from the baseline, it is not surprising to find large inconsistencies in Emergy results, in particular when comparing systems that use different baselines at different times and on different spatial scales [66]. As a consequence, it is not necessarily obvious that Emergy is the appropriate indicator to estimate the environmental work required to regenerate what has been consumed, because the future 
temporal (and spatial) conditions for resource formation are likely to be very different from those of the past. Furthermore, UEV calculation is based on rather crude assumptions and results are therefore seldom reproducible $[36,42,67]$ and cannot be validated a posteriori. In this respect, Emergy and LCA share the same limitations. However, due to its "memorization" (and non-conservative) character, Emergy is intuitively even more dependent on the degree of detail at which the system under study is described than LCA [34]. How to deal with the different uncertainty issues related to the calculation of UEVs is further discussed in [35], where the use of matrix inversion principles is recommended to calculate more consistent UEVs to avoid applying the baseline.

The effect of using the baseline also has further relevant impacts downstream in the EGS-UEV calculation. First, spatial and temporal variability is not included within the UEV models, which are assumed to be in steady-state conditions for a reference (undefined) year of EGS production and without specific downscaling properties to regional boundaries, i.e. the UEVs are representative of "average" global conditions. As a consequence, the Emergy value of EGSs that have a meaningful dependence on the regional scale, such as some provisioning (e.g. freshwater availability or biotic resources) or supporting (e.g. pollination) services, cannot be representative of the different local conditions around the globe. Second, the Emergy accounting procedure usually models the Emergy input associated with local resources (e.g. rain, sun) in such a manner that the Emergy input to a system does not fully contribute to the system development but instead a fraction is usually exported [68]. In this regard, we argue that only the equivalent (solar) energy that was actually needed to generate a given resource should be accounted for to give a more consistent evaluation of how much available energy is embodied in the UEV [35]. Finally, by using the baseline, the notion of "history" of resource formation (i.e. the accounting for solar inputs over geological time scales; [42]), as apparently stems from the definition of Emergy as the available energy of one kind used up directly and indirectly to generate resources and products [25], seems to be completely missing. This is particularly true for most of the EGSs whose turnover time is greater than one year, those which are usually considered as non-renewable, i.e. minerals, metal ores, topsoil, groundwater, etc. Indeed, assigning with a top-down perspective a global production value (i.e. the baseline) to the annual flow of the resource (see Eq. (1)), means neither assessing how much available energy is memorized within the "life cycle" chain upstream of that ecosystem good or service, nor even being able to approximate the environmental work required to replace it in the future. The assumption that all the different biogeochemical flows, on the global scale, are coproducts of the same annual contribution of solar Emergy (i.e. the baseline) makes the UEVs different solely because of the relative amounts of the flows on the globe. As a result, the lower the amount of the EGS flow (which of course depends on the ratio between stock and turnover time, see Eq. (2)) the higher the UEV, but without a clear link to the actual effort invested by Nature in generating that flow, which remains eventually unknown. Hence, it seems inappropriate hierarchizing UEVs of EGSs and considering them as indicators of "natural" efficiency.

On the other hand, the LCA method is less consistent than Emergy in the accounting for EGSs, where a limited number of EGSs is currently considered in LCIs [22] (compare Tab. 1 vs. Tab. 2). While Emergy attempts to evaluate the energy memory associated with information and with ecosystem services (e.g. provisioning and regulating services such as rain, tide and evapotranspiration, or supporting services such as soil formation and photosynthesis [22, 27$30,51,52]$ ), LCA does not generally account for those inputs because they are not specifically required/solicited by the economic systems, and are assumed to be freely available and not scarce. This approach indeed stems from the user-side perspective of LCA as compared with the donor-side perspective of Emergy. As a result, the combination of UEVs with existing LCI databases is not a trivial task, because of the complexity of the natural systems behind them and the missing inputs, which indeed are proven to 
sustain human economies and should not be disregarded [35]. Research is ongoing in the LCA community to deal with this issue $[7,16-21]$. It is expected that the system boundary of LCI will be enlarged in the near future with inclusion of a meaningful set of ecosystem services [69], where eventually the UEV library outlined in Table 2 might be harmonized.

\section{Conclusions}

As the "usefulness" of numerous, indirect EGSs remains unidentified, their contribution is likely to be minimized by using more traditional approaches based on solely monetary units (e.g. contingent valuation, willingness to pay). A relevant indicator for LCIA needs to accept scope enlargement and refining. Emergy accounts for the ecosystem contribution invested in order to obtain a product and therefore can potentially provide insightful information on the longterm sustainability of human processes [32]. The integration of Emergy into LCA might deliver a paradigm shift to the latter, by providing an assessment perspective larger than the common anthropocentric one, toward a Nature-oriented evaluation of natural resource use. Emergy appears as a complementary approach to LCA, because it goes beyond the accounting for natural resources by evaluating the environmental work needed for their formation. It provides a unique common metric of evaluation (i.e. the seJ), which enables one to put all EGSs on the same scale. However, Emergy has been strongly criticized due to its lack of overall consistency, which has hampered its acceptance and use during the past years $[35,36,42,67,68,70,71]$. It has been observed that the integration between Emergy and LCA is feasible but limited by a number of uncertainty elements and by an unclear definition of the resource UEV calculation [37].

Despite the fact that the use of the extensive perspective of Emergy seems crucial to evaluate in LCA the support provided by ecosystem functions to technological processes [32], there is a strong need to standardize the calculation procedure of EGSs in Emergy before including it in LCA, in particular with regard to the regulating and cultural services' categories [22]. Indeed, the Emergy content (or UEV) of EGSs does not apparently have a direct or tangible value for humans due to the not completely clear meaning of the "donor- or ecologicaloriented" definition of Emergy. The concept of ecosystem services ultimately embodies a user-side perspective. The cultural services, in particular, can be perceived as even more mankind-centered because they are directly beneficial only for humans, while other EGSs such as water regulation or pollination, in turn, directly influence the well-being of non-human species, while only indirectly providing benefits to humans. Commonly, when comparing systems, it is indicated that "the higher the UEV, the lower the efficiency of the process but the higher the quality of the product, because larger environmental cost can be associated with it". However, this might not be always the case and the value of Emergy results should not be generalized as such. A lower UEV means that a lower amount of natural inputs (e.g., rain) is bestowed by the geobiosphere to obtain the final EGS or the same amount of inputs is necessary to obtain more quantity of a natural resource. Accordingly, we cannot state whether this lower amount of natural inputs is also a marker of less environmental impact, because the amount of environmental work can neither be related to the notion of scarcity nor interpreted as an entity valuable per se to be protected. In the conventional interpretation, however, the UEV is considered a measure of the scale of energy convergence, whereby higher UEVs are commonly associated with higher "environmental impact" following a sort of precautionary principle.

Scientists from the Emergy community, for instance through interdisciplinary studies (e.g. ecological network analysis, resilience, ascendency e.g. [72-75]), should insist on trying to clarify the rationale behind the UEV as an indicator, which despite the potential seems to be coarsely used. Research is ongoing to refine the UEVs for elementary flows of EGSs, to harmonize the calculation procedures with regard to the allocation principles, which are quite different in Emergy than in LCA models [34], and to 
expand the scope of the LCI system boundaries [35]. The Emergy-based mid-point impact characterization approach illustrated in this paper can provide, in the end, useful insights on how to face these constraints and future challenges.

\section{Acknowledgements}

Benedetto Rugani and Damien Arbault wish to thank the administration of the National Research Fund of Luxembourg (FNR), which supported this work (co-funded under the Marie Curie Actions of the European Commission: FP7COFUND).

\section{References}

[1] Millennium Ecosystem Assessment (MEA 2005), http://www.millenniumassessment. org/

[2] The Economics of Ecosystems and Biodiversity (TEEB 2010), http://www. teebweb.org/

[3] R. Costanza, R. D'Arge, R. De Groot, S. Farber, M. Grasso, B. Hannon, S. Naeem, K. Limburg, J. Paruelo, R.V. O'Neill, R. Raskin, P. Sutton, M. van den Belt, Nature 387 (1997) 253-260

[4] European Commission (2010), ILCD Handbook - International reference Life Cycle Data System, General guide for Life Cycle Assessment - Detailed guidance. First edition, European Commission Directorate General Joint Research Centre (JRC) Institute for Environment and Sustainability Ispra (IT)

[5] ISO (2006), ISO 14040 International Standard. In: Environmental Management - Life Cycle Assessment - Principles and Framework, International Organisation for Standardization Geneva $(\mathrm{CH})$

[6] European Commission (2010), ILCD Handbook - International reference Life Cycle Data System. Framework and Requirements for Life Cycle Impact Assessment Models and Indicators. First edition. European Commission Directorate General Joint Research Centre (JRC) Institute for Environment and Sustainability Ispra (IT)

[7] M. Curran, L. de Baan, A. de Schryver, R. van Zelm, S. Hellweg, T. Koellner, G. Sonnemann, M.A.J. Huijbregts, Environ. Sci. Technol. 45 (2011) 70-79

[8] M.E. Bösch, S. Hellweg, M.A.J. Huijbregts, R. Frischknecht, Int. J. Life Cycle Assess. 12 (2007) 181-190
[9] J. Dewulf, M.B. Bösch, B. De Meester, G. Van der Vorst, H. Van Langenhove, S. Hellweg, M.A.J. Huijbregts, Environ. Sci. Technol. 41 (2007) 8477-8483

[10] B. Rugani, M.A.J. Huijbregts, C. Mutel, S. Bastianoni, S. Hellweg, Environ. Sci. Technol. 45 (2011) 5426-5433

[11] J.B. Guinée, M. Gorrée, R. Heijungs, G. Huppes, R. Kleijn, A. de Koning, L. van Oers, A. Wegener Sleeswijk, S. Suh, H.A. Udo de Haes, H. de Bruijn, R. van Duin, M.A.J. Huijbregts, Handbook on Life Cycle Assessment. Operational Guide to the ISO standards Kluwer Academic Publisher: Dordrecht (NL), 2002

[12] O. Jolliet, M. Margni, R. Charles, S. Humbert, J. Payet, G. Rebitzer, R. Rosenbaum, Int. J. Life Cycle Assess. 8 (2003) 324-330

[13] M. Hauschild, J. Potting, Spatial differentiation in life cycle impact assessment. The EDIP 2003 methodology. Environmental News No. 80 Danish Environmental Protection Agency Copenhagen (DK), 2005

[14] M. Goedkoop, R. Heijungs, M.A.J. Huijbregts, A. de Schryver, J. Struijs, R. van Zelm, ReCiPe 2008. A life cycle impact assessment method which comprises harmonised category indicators at the midpoint and the endpoint level. First edition Report I: Characterisation Ministerie van VROM Den Haag (NL), 2008

[15] G. Brand, A. Scheidegger, O. Schwank, A. Braunschweig, Weighting in Ecobalances with the Ecoscarcity Method: Ecofactors 1997. Environmental Series No. 297 Swiss Federal Agency for the Environment Bern (CH), 1998

[16] LULCIA (2008-2011) T. Koellner (Project Leader) Partners (in alphabetical order by last name): A.P. Arena, T. Beck, U. Bos, M. Brandão, B. Civit, L. Deschenes, M. Margni, L. Milà i Canals, R. Müller-Wenk, R. Saad, B. Wittstock : Operational Characterization Factors for Land use Impacts on Biodiversity and Ecosystem Services in the Life-Cycle Impact Assessment - Compatible with the Framework of the UNEP-SETAC Life Cycle Initiative (LULCIA): http:// www.estis.net/sites/lcinit/default.asp? site $=$ lcinit $\backslash$ \&page_id $=337831 \mathrm{BE}-0 \mathrm{C} 0 \mathrm{~A}$ 4DC9-AEE5-9DECD1F082D8

[17] L. de Baan, R. Alkemade, T. Koellner, Int. J. Life Cycle Assess. 18 (2012) 1216-1230

[18] R. Müller-Wenk, M. Brandão, Int. J. Life Cycle Assess. 15 (2010) 172-182

[19] M. Brandão, L. Milà i Canals, Int. J. Life Cycle Assess. 18 (2012) 1243-1252

[20] R. Saad, M. Margni, Int. J. Life Cycle Assess. 18 (2012) 1253-1264 
[21] T. Koellner, L. de Baan, T. Beck, M. Brandão, L. Milà i Canals, B. Civit, M. Margni, R. Saad, D. Maia de Souza, R. Müller-Wenk, Int. J. Life Cycle Assess. 18 (2012) 1188-1202

[22] Y. Zhang, S. Singh, A. Baral, B.R. Bakshi, Environ. Sci. Technol. 44 (2010) 2232-2242

[23] The Ecoinvent database v2.2, http://www. ecoinvent.org/database/

[24] H.T. Odum, Science 242 (1988) 1132-1139

[25] H.T. Odum, Environmental Accounting: Emergy and Environmental Decision Making John Wiley and Sons, New York USA, 1996

[26] F.M. Pulselli, S. Bastianoni, N. Marchettini, E. Tiezzi, The Road to Sustainability, GDP and the Future Generations, WIT Press: Southampton, UK, 2008

[27] F.M. Pulselli, L. Coscieme, S. Bastianoni, Ecol. Modell. 222 (2011) 2924-2928

[28] S. Ulgiati, M.T. Brown, Commun. Nonlinear Sci. Numer. Simul. 14 (2009) 310-321

[29] M.D.B. Watanabe, E. Ortega, Environ. Sci. Policy 14 (2011) 594-604

[30] H.T. Odum, E.P. Odum, Ecosystems 3 (2000) 21-23

[31] M.T. Brown, M.J. Cohen, E. Bardi, W.W. Ingwersen, Aquat. Sci. 68 (2006) 254-277

[32] W.W. Ingwersen, J. Ind. Ecol. 15 (2011) 550567

[33] M. Raugei et al., Nested Emergy Analyses: Moving ahead from the spreadsheet platform. In: Brown et al. (Eds.), Emergy Synthesis 4, Center for Environmental Policy University of Florida: Gainesville FL USA, 2007

[34] A. Marvuglia, B. Rugani, G. Rios, Y. Pigné, E. Benetto, L. Tiruta-Barna, Revue de Métallurgie 110 (2013) 87-94

[35] B. Rugani, E. Benetto, Environ. Sci. Technol. 46 (2012) 4701-4712

[36] E. Sciubba, S. Ulgiati, Energy 30 (2005) 19531988

[37] M. Raugei, Ecol. Modell. 222 (2012) 3821-3822

[38] H.T. Odum, Handbook of Emergy Evaluation. Folio\#2. Emergy of Global Processes, Centre for Environmental Policy University of Florida: Gainesville, USA, 2000

[39] M.T. Brown, S. Ulgiati, Ecol. Modell. 221 (2010) 2501-2508

[40] D.E. Campbell, Environ. Monit. Assess. 51 (1998) 531-569

[41] R.M. Pulselli, J. Environ. Manage. 91 (2010) 2349-2357

[42] J.L. Hau, B.R. Bakshi, Ecol. Modell. 178 (2004) 215-225

[43] M.T. Brown, S. Ulgiati, AMBIO 28 (1999) 486493
[44] S. Ulgiati, A. Zucaro, P.P. Franzese, Ecol. Econ. 70 (2011) 778-787

[45] S. Ulgiati, M.T. Brown, J. Clean. Prod. 10 (2002) 335-348

[46] U. Geber, J. Björklund, Ecol. Eng. 19 (2002) 97-117

[47] D.E. Campbell, Northeastern Natur. 11 (1998) 355-424

[48] J.F. Martin, Ecol. Eng. 18 (2002) 265-286

[49] S.-L. Huang, Y.-H. Chen, F.-Y. Kuo, S.-H. Wang, Ecol. Complex. 8 (2011) 38-50

[50] M. Montesino, Ecosystem services in emergy term: Danish energy crops. M.Sc. Thesis University of Copenhagen, DK, 2010

[51] M.J. Cohen, M.T. Brown, K.D. Shepherd, Agric. Ecosyst. Environ. 114 (2006) 249-269

[52] D.E. Campbell, Environ. Sci. Technol. 35 (2001) 2867-2873

[53] D.R. Tilley, W.T. Swank, J. Environ. Manage. 69 (2003) 213-227

[54] H.T. Odum, S.J. Doherty, F.N. Scatena, P.A. Kharecha, For. Sci. 46 (2000) 521-530

[55] D. Kang, S.S. Park, J. Environ. Manage. 66 (2002) 293-306

[56] M.T. Brown, T.R. McClanahan, Ecol. Modell. 91 (1996) 105-130

[57] V. Voora, C. Thrift, Using Emergy to Value Ecosystem Goods and Services, Alberta Environment - International Institute for Sustainable Development, Winnipeg Manitoba, CA, 2010

[58] A.A. Buenfil, Emergy Evaluation of Water, Ph.D. Dissertation University of Florida Gainesville, USA, 2001

[59] S. Bastianoni, D.E. Campbell, L. Susani, E. Tiezzi, Ecol. Modell. 186 (2005) 212-220

[60] M.T. Brown, M.J. Cohen, Emergy and Network Analysis, In: S.E. Jörgensen, B. Fath (Eds.), Encyclopedia of Ecology Elsevier, Amsterdam, NL, 2008

[61] M.J. Cohen et al., Computing the Unit Emergy Value of Crustal Elements, In Brown et al. (Eds.), Emergy Synthesis 4, Center for Environmental Policy University of Florida: Gainesville FL, USA, 2007

[62] M.T. Brown, G. Protano, S. Ulgiati, Ecol. Modell. 222 (2011) 879-887

[63] European Reference Life Cycle Database II (ELCD), http://lca.jrc.ec.europa.eu/ lcainfohub/datasetCategories.vm

[64] J. Babiè, Emergy Analysis of the Salt Production Process at the SeèOvlje Saltpans Slovenia. In Brown et al. (Eds.), Emergy Synthesis 3, Center for Environmental Policy University of Florida: Gainesville FL, USA, 2005

[65] M.T. Brown, R.D. Woithe, C.L. Montague, H.T. Odum, E.C. Odum, Emergy analysis perspectives of the Exxon Valdez oil spill in 
Prince William Sound, Alaska. Final Report to the Cousteau Society. Gainesville, FL: Center for Wetlands, University of Florida; USA, 1993, p. 114

[66] D.E. Campbell, A revised solar transformity for tidal energy received by the earth and dissipated globally: Implications for Emergy Analysis, In Brown M.T. (Ed.), Emergy Synthesis 1, Center for Environmental Policy University of Florida: Gainesville, USA, 2000

[67] E. Sciubba, Energy 35 (2010) 3696-3706

[68] D.E Campbell et al., Current Technical Problems in Emergy Analysis, In Brown et al. (Eds.), Emergy Synthesis 3, Center for Environmental Policy University of Florida: Gainesville FL, USA, 2005
[69] B.P. Weidema, C. Bauer, R. Hischier, C. Mutel, T. Nemecek, C.O. Vadenbo, G. Wernet, Overview and Methodology. Data Quality Guideline for the Ecoinvent Database Version 3, Ecoinvent Report 1(v3) The Ecoinvent Centre: St. Gallen, CH, 2011

[70] C.J. Cleveland, R.K. Kaufmann, D.I. Stern, Ecol. Econ. 32 (2000) 301-317

[71] B.A. Mansson, J.M. McGlade, Oecologia 93 (1993) 582-596

[72] V. Christensen, Ecol. Modell. 72 (1994) 129144

[73] B.C. Patten, Ecol. Modell. 79 (1995) 75-84

[74] D.K. Gattie, N.N. Kellam, H.J. Turk, Ecol. Modell. 208 (2007) 25-40

[75] S. Chen, B.D. Fath, B. Chen, Proc. Environ. Sci. 2 (2010) 720-724 